International Mathematical Forum, Vol. 8, 2013, no. 28, 1375 - 1384

HIKARI Ltd, www.m-hikari.com

http://dx.doi.org/10.12988/imf.2013.36116

\title{
Enchanced Growth Development through Better Information System Design: The System Analyst Perspective
}

\author{
Z. Manoussaridis \\ Aristotle University of Thessaloniki, School of Technology \\ Dept. of Physical Planning and Growth Development \\ 59100 Veria, Greece \\ manzac@eng.auth.gr \\ C. Mamaloukas \\ Department of Statistics \\ Athens University of Economics and Business \\ Athens, 10434, Greece \\ mamkris@aueb.gr \\ M. Sagheb-Tehrani \\ College of Business Technology and Communication \\ School of Business Bemidji State University 1500 Birchmount Dr \\ NE, Decker Hall, Bemidji, MN 56601, USA \\ mtehrani@bemidjistate.edu
}

Copyright (c) 2013 Z. Manoussaridis et al. This is an open access article distributed under the Creative Commons Attribution License, which permits unrestricted use, distribution, and reproduction in any medium, provided the original work is properly cited.

\begin{abstract}
Nowadays, many industrial countries are being transformed from industrial economies to knowledge and information-based service economies, whereas manufacturing has been moving to low-wage countries i.e. China, India etc. In knowledge societies, information and knowledge are key parts in creating wealth. To achieve growth de-
\end{abstract}


velopment, there is a need to continuously distributing or creating new knowledge and information. Appropriate information systems are needed to optimize the flow of information and knowledge in the organizations to help planners and decision makers.

Better information systems can increase the effectiveness and the quality of crucial activities like spatial analysis, strategic objectives setting, long-range planning and decision-making. Respectively, this effect can enhance the potentials for growth development of a regional or a national economy. The dimension of an information system's role and responsibility can play a significant role in the outset of the information systems development (ISD) process. These aspects have not been the subject of much debate and attention in ISD. In this paper an attempt is made to conceptualize the dimension of information systems' roles and responsibilities. This comprises an initial step towards exploration of the relationship between the dimension of information systems' roles and responsibilities and ISD and respectively their potential impact in growth development performances.

\section{Mathematics Subject Classification: 68U35}

Keywords: Information technology (IT), Information Systems development (ISD), Decision-making, Growth development

\section{Introduction}

Public and private organizations all over the world are focusing on information as a key resource [13]. The availability and use of information systems has grown to the point of being an important commodity [7]. It is widely recognized that information systems knowledge is vital for managers, planners and decision-makers because most organizations need them in order to operate effectively $[13,16]$. The organization environment has altered due to worldwide changes. One of the important changes is the transformation of industrial economies and societies into knowledge and information-based service economies.

Information systems provide the communication and analytical power that organizations need for carrying out their activities. Major industrial countries are being transformed from industrial economies to knowledge and informationbased service economies, whereas manufacturing has been moving to low-wage countries i.e. China, India etc. In knowledge societies, information and knowledge are key parts in creating wealth. To be effective and successful in management, planning and decision-making, there is a need to continuously distributing or creating new knowledge and information. These tasks mainly involve working with, distributing or creating new knowledge and information. According to SIBIS [23], knowledge and information work increases steadily in 
EU countries in 21st century, with the north European countries to have faster development rates. Relevant information systems are needed to optimize the flow of information and knowledge in the organizations to help decision makers.

The development of IS incorporates many dimensions such as IS methodology, IS type, hardware and software platform and information system's role and responsibility. A summary of related works on ISD has given by Dewett et al [7]. Their common characteristic is that of information technology primary benefits. The significance of IS role and its responsibilities in business environments have been pointed by Sagheb-Tehrani [22]. This work tries to identify the impact of information systems' roles and responsibilities in ISD process and respectively in growth development. This fundamental dimension can be scattered in sub-dimensions such as roles of IS, responsibilities of IS, users, types of IS, organization structure, management levels, organization culture, policy and size of organization (see fig.1).

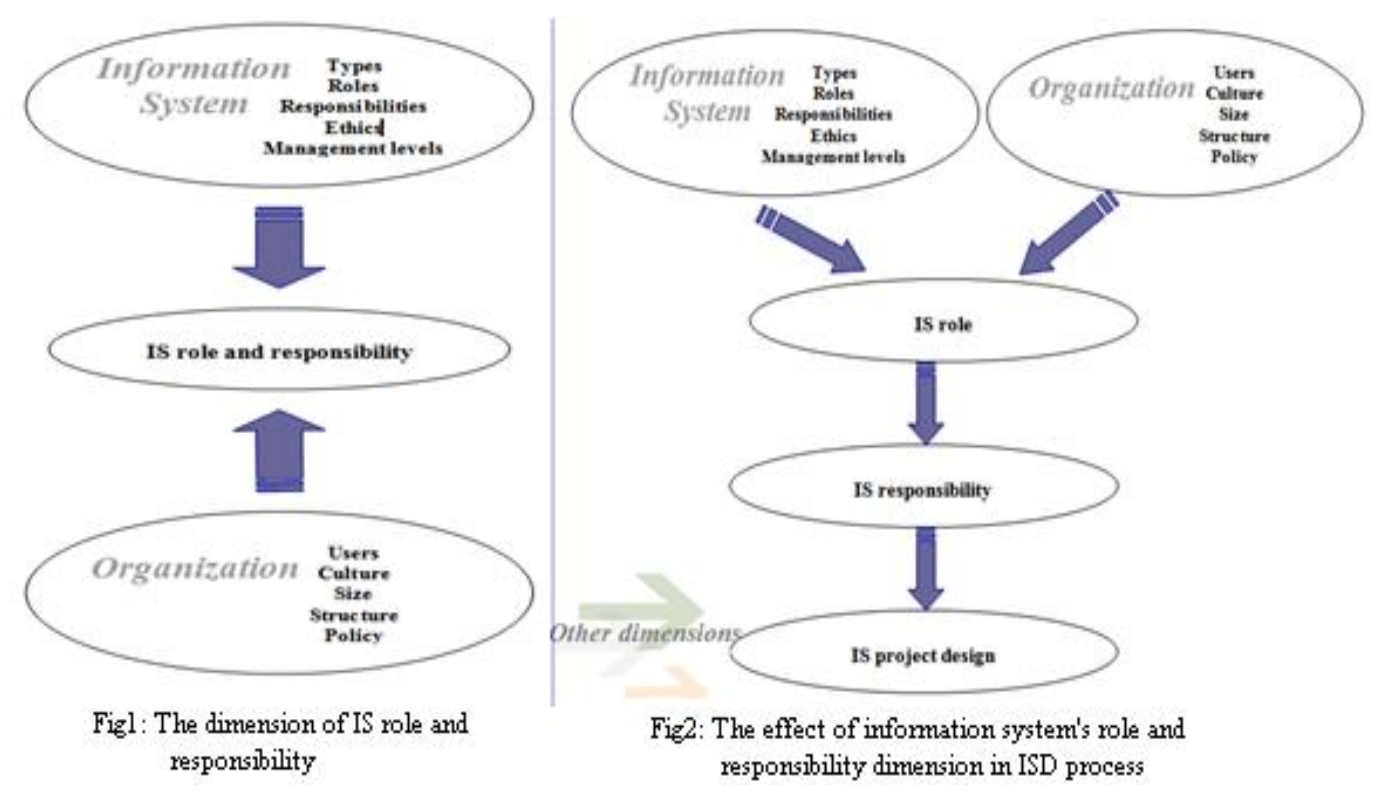

\section{Information System Definition}

This paper approaches the fundamental dimension of information system's role and its responsibilities by examining various important sub-dimensions and their relationships involved in the development process. There are many diverse definitions of information systems. Before specifying the definition of information system, one must have a good understanding of "Data" versus "Information". These terms have been used interchangeably; however, they are not interchangeable. Data refer to facts and figures that are relatively meaningless to the user [19]. Put it differently, data refer to streams of raw facts 
representing events occurring in organizations or the physical environment before they have been organized and arranged into a form that people can conceive and utilize [19]. Information refers to data that have been processed into a form that is meaningful and useful to the user.

An information system refers to a set of interrelated components that collect or retrieve process, store and distribute information to support decision making, coordination, control and analysis in an organization [18]. Any IS must achieve both "technical" and "psychological" success. Technical success refers to the actual performance of the systems matches its specification. Psychological success refers to the degree to which the end user has confidence in the system. One can say that achievement in any of them can contribute to the other one. This paper is mainly concerned with the latter one.

\section{User dimension}

There are diverse classifications of IS user [10]. Users are the people who actually use the system to perform or support the work to be completed. In many cases, they set the system requirements and performance expectation for the organizations to be built [25]. In general terms, any person who is affected by IS directly or indirectly could be perceived as a user. Anything a human uses, ranging from everyday objects such as chairs and vacuum cleaners to technically advanced products such as copier machines and computers should be user friendly. A product is user friendly if most users can use it easily with minimum training. A user-friendly information system is more productive because the user wastes less time and effort struggling with system features that get in the way of doing work. A technology is user hostile when it is difficult to use [1]. A user-friendly information system helps the user focuses on the actual problem rather than on the computerized tool being used to solve this problem. A user-friendly information system is designed to minimize errors by users and to make it easy to correct any user errors that may occur. To have a user friendly, efficient and effective IS, different methods must be combined. Therefore, the user dimension is significant in both the "technical" and "psychological" success of IS which affects the dimension of IS roles and responsibilities.

\section{IS types, roles and responsibilities}

Information systems and organizations interact each other. Information systems must be aligned with the organization to provide information for different management levels within the organizations. An information system is an important tool to support various organizational level activities. According to 
Anthony [1] there are three kinds of management tasks: strategic planning, management control and operational control. Managers at the top of the organizational hierarchy who are responsible for making long-range decisions are referred to as senior managers or other similar names. Middle level managers are in the middle of the organizational hierarchy in an organization who are responsible for carrying out the plans and goals of the senior management. The lowest level has been called the operational managers who monitor the day-to-day activities of the organization. Each of the above mentioned management levels require a particular IS that supports these tasks $[3,6,15,19$, 20]. In modern organization environments there are various types of IS (see table1).

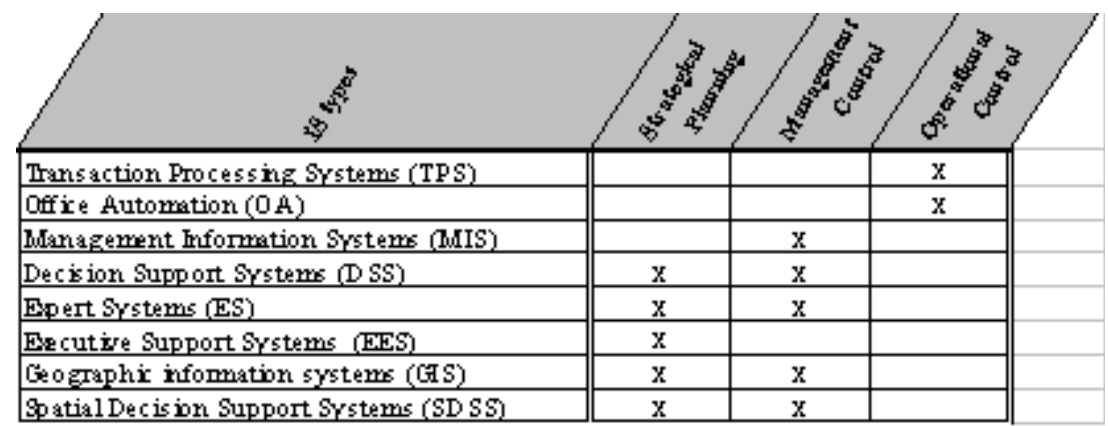

Tablel: IS types and organizational tasks

The role of IS in analyzing, planning and decision-making is quite significant. IS can play many different roles, both for the user and the organization. However, IS comprises a dispensable tool that supports users to solve various problems. It is important to differentiate between the different roles which an IS can have. One way to describe the possible roles of an information system is by analogy with the roles played by people. There are actually three roles that an IS can have (see table2).

Which is the actual role of an IS remains often an underestimated issue. Implementing different roles of IS may have its own problem. But, it is important to consider thoroughly the question of what role an IS play in the outset of an information system development (ISD) process.

Responsibility refers to accepting the potential costs, duties, and obligations associated with the decisions one makes [19]. Responsibility is one of the key elements in the ISD process. There is a view, which believes that in use of expert systems the system itself should not be alone responsible. The responsibility of IS is another important issue, because the utilization of IS is widespread. There have been many wrong plans inequitable decisions and undesirable accidents, where information technology was involved. Who is responsible for such a mistake, the system, the user, the designer or all? According to our consideration, the responsibilities of an IS depends upon the roles of an IS (see table3). 


\begin{tabular}{|c|c|c|c|}
\hline Roleo & Actiono & Roleo & Responsibilityo \\
\hline a) $\rightarrow$ Dependanto & The IS camies out tasks under the user controlo & a) $\rightarrow$ Dependanto & The user is responsibleo \\
\hline b) $\rightarrow$ Dominanto & The:IS."prompts"'andtheuser."acts". o & b) $\rightarrow$ Dominanto & The system designer is responsible for the system outcomeso \\
\hline c) $\rightarrow$ Co-operatoro & Synergy between IS andusero & c) $\rightarrow$ Co-operatoro & Join responsibility of the user and the designero \\
\hline
\end{tabular}

\section{Organization}

The introduction of IS involves much more than computer hardware and software. It also comprises changes in skills, attitudes, management, power balance, jobs and organization. One cannot install new technology without considering the people who must work with it [4]. The interaction between IS and organization is very complex and influenced by many factors such as the organization's structure, politics, culture, size, environment, operating procedures and management decisions. Designing IS means redesigning the organization. A basic question is whether or not IS will lead to centralization or decentralization. Centralization refers to the extent to which decisions making authority is concentrated in an organization [21]. Regarding centralization, by enabling managers to obtain more information, more quickly and accurately, IS reduce uncertainty and lead managers to make decisions that they otherwise may not have made [17]. Considering decentralization, an IS enables lower and middle level managers to stay better informed about the organization's overall situation and about the status of current problems and outcomes allowing them to be more globally optimized in their work [2].

The size of an organization impacts the size of IS and its risk. The larger the IS project, as indicated by the amount of money spent, the time allocated for implementation, the people involved and the number of sub-systems affected, the greater risk is possible. Further, others have argued that IS reduces the size of organization because IS will lead to fewer numbers of middle managers [9]. On the other hand, the literature suggests that IS may allow organizations to become bigger [14]. There has been little or no research into these issues and future research is needed to address this matter.

The ability of an organization to learn, develop memory, and share knowledge is dependent on its culture. Culture can be defined as a complex pattern of beliefs, expectations, ideas, values, attitudes and behaviours shared by the members of an organization [24]. IS can facilitate the sharing of beliefs, values and norms because it allows for the quick and clear transmission of information among people within organization. Therefore, IS can moderate the effect of culture on employee beliefs, values, attitudes and behaviours in different ways.

The organizational structure can influence the above-mentioned dimen- 
sions. The hierarchical and network approaches to management obviously present important differences, and each have successes and failures. There is, in fact, no single, best way to manage all organizations. Research considering organizational structure has always resulted in conflicting research findings because of the existence of contingency factors such as the environment, strategy or technology that may effect the nature of the relationship $[5,8]$. Rather, the best management is contingent on characteristics of the organization being managed.

\section{Conceptualization of IS role and responsi- bility}

As mentioned before, IS can play multifold roles, both for the user and the organization. It is very significant for an IS developer to differentiate between the various roles of IS at the outset of developing such systems. This can provide a better understanding of the motivation of developing IS projects which can contribute to a successful implementation of IS projects.

This can result in better information and knowledge flow inside and outside organizations. As regards urban planning and growth development, better IS can increase the effectiveness of critical activities like spatial analysis, planning, decision-making etc.

Furthermore, the responsibility of IS varies from one system to another, depending upon its role. A conceptualization of abovementioned sub-dimensions together with their structural linkage is presented in fig2.

\section{Conclusions}

This paper discusses the impact of information system's role and its responsibility in ISD. By developing better IS, we can actually increase the effectiveness and the quality of spatial analysis, strategic objectives setting, long-range planning, and decision-making in the areas of urban planning and growth development [11, 12, 16]. Respectively, this can effect positively the growth development of a regional or a national economy.

The presented conceptualization allows one to comprehend the significance of IS role and responsibility dimension. This helps in defining the roles and responsibilities of an IS at the beginning of developing an IS project. Indirect benefits occurring from this conceptual model include the scope for obtaining insight about this dimension contribution to a more successful ISD process. Furthermore, this work may provide a basis for further research in ISD. One direction that further research might take is more studies on a particular information system's role and responsibility. Another direction would be more 
efforts to develop an exhaustive conceptual framework that can effectively lead to a successful ISD. Another direction would be to use the conceptual model presented here in a case study of planning or growth development. Research in this field should contribute to the knowledge of ISD so that IS, designated to support urban planning and growth development activities, can be implemented successfully.

\section{References}

[1] Anthony R.N (1965): Planning and control systems: A framework for analysis, Harvard University Press.

[2] Argyres N.S (1999): The impact of information technology on coordination, evidence from the B-2 "stealth" bomber, Organization Science, 10(2), pp.162-180.

[3] Beulens A.M, Nunen V.E (1988): The use of expert system technology in DSS, Decision Support Systems 4 (1988).

[4] Bostrom R.P and Heinen J.S (1977): MIS Problems and Failures: A socioTechnical Perspective, Part I: The Causes, MIS Quarterly 1, Sep 1977, Part II: The Application of Socio-Technical Theory, MIS Quarterly, Dec 1977.

[5] Child J (1972): Organizational structure, environment and performance, the role of strategic choice, Sociology 6, pp.1-22.

[6] deMers, M.N. (1997) Fundamentals of Geographic Information Systems. John Wiley and Sons.

[7] Dewett T, Jones G.R (2001): The role of information technology in organization: a review, model, and assessment, Journal of Management 27(2001) pp. 313-346.

[8] Fry L.W (1982): Technology structure research, three critical issues, Academy of Management Journal 25(3), pp.532-552.

[9] Groth L (1999): Future Organization Design, John Wiley and Sons.

[10] Guimaraes T (1999): Empirically Testing the Relationship Between EndUser Computing Problems and Information Center Success Factors, Decision Sciences, Spring, 1999. 
[11] Hamilton, A., Trodd, N., Zhang, X., Fernando, T., and Watson, K., (2001) Learning Through Visual Systems To Enhance The Urban Planning Process, Environment and Planning B: Planning \& Design, 28 (6) November, pp. 833-845.

[12] James Philip, Fernando Terrence, Hamilton A. and Curwell St. (2004) Enhancing the Decision-making Process in Urban Spatial Planning Using Advanced ICT, Technical Paper: Technologies for new ways of working, Workshop at the University of Salford 29th and 30th March 2004.

[13] Haug S, Cummings M, McCubbrey D.J (2002): Management Information Systems for the Information Age, 3rd ed., McGraw-Hill.

[14] Huber G.P (1990): A theory of the effects of advanced information technology on organization design, intelligence, and decision making, Academy of Management Review, 15(1), pp.47-71.

[15] Iliadis L. (2005): A decision support system applying an integrated Fuzzy model for long - term forest fire risk estimation, Environmental Modelling And Software, Elsevier Science, Vol. 20, Issue 5, May 2005, pp. 613-621.

[16] Kammeier, H. (1999). New tools for spatial analysis and planning as components of an incremental planning-support system, Environment and Planning B: Planning and Design, 26(3), pp. 365-380.

[17] McLeod R.Jr, Schell G (2001): Management Information Systems, 8th edition, Prentice Hall.

[18] Lado A.A, Zhang M.J (1998): Expert systems, knowledge development and utilization and sustained competitive advantage: a resource-based model, Journal of Management, 24(4), pp.489-509.

[19] Laudon K.C, Laudon J.P (2002): Management Information Systems, 7th edition, Prentice Hall.

[20] Manussaridis Z., Mamaloukas Ch., Spartalis N., (2002) "A Prototype DSS for Varied Activities Routing", International Journal of Computational and Numerical Analysis and Applications, IJCNAA, Co. Vol. 1 No. 3, pp. 311-322, ISSN 1311-6789.

[21] Pfeffer J (1981): Power in organization, Boston Pitman.

[22] Sagheb-Tehrani M. (2003): Information System's Roles And Responsibilities: Towards A Conceptual Model, ACM, Computer And Society, Volume 32, Issue 3, , USA. 
[23] SIBIS (Statistical Indicators Benchmarking the Information Society) (2003), WP4 - D4.3.3 eEurope 2005 Key Figures for Benchmarking EU15, IST-2000-26276, Databank Consulting, April 2003.

[24] Trice H.H, Beyer J.M (1993): The Culture of Work Organizations, Englewood Cliffs, NJ, Prentice Hall.

[25] Whitten J.L, Bentley L.D, Dittman K.C (2001): Systems Analysis and Design Methods, 5th edition, McGraw Hill.

Received: June 6, 2013 